\title{
Progress in low-cost n-type silicon solar cell technology
}

\author{
L.J. Geerligs, ${ }^{1}$ I.G. Romijn, ${ }^{1}$ A.R. Burgers, ${ }^{1}$ N. Guillevin, ${ }^{1}$ A.W. Weeber, ${ }^{1}$ J.H. Bultman, ${ }^{1}$ \\ Hongfang Wang, ${ }^{2}$ Fang Lang, ${ }^{2}$ Wenchao Zhao, ${ }^{2}$ Gaofei Li, ${ }^{2}$ Zhiyan $\mathrm{Hu},{ }^{2}$ Jingfeng Xiong, ${ }^{2}$ \\ Ard Vlooswijk ${ }^{3}$ \\ ${ }^{1}$ ECN Solar Energy, Petten, Netherlands; ${ }^{2}$ Yingli Green Energy Holding Co., LTD, Baoding, China; \\ ${ }^{3}$ Tempress Systems, Vaassen, Netherlands
}

\begin{abstract}
This article will review our recent progress in development of high-efficiency cells on n-type monocrystalline $\mathrm{Si}$ wafers. With boron-doped front emitter, phosphorous BSF, and screen-printed metallisation, at this moment such cells reach an efficiency of over $19 \%$. We describe recent results of processing with reduced front contact area, and improved BSF and improved rear surface passivation, which are key parameters that limit the cell efficiency. The improved processing leads to an efficiency of $20 \%$. The cell process has also been adopted for fabrication of metal-wrap-through back-contact cells. Without the improved contact recombination and BSF, an MWT cell efficiency of $19.7 \%$ is reached, $0.3 \%$ higher than the corresponding 'standard' (non-back-contact) cells.
\end{abstract}

Index Terms - photovoltaic cells, silicon, n-type, bifacial.

\section{INTRODUCTION}

Crystalline silicon solar cells based on n-type monocrystalline wafers offer considerable advantages for industrial production of high-efficiency photovoltaic modules [1]. Particular advantages are i) high minority carrier lifetime of n-type $\mathrm{Si} \mathrm{Cz}$ wafers, not affected by light induced degradation and tolerant to many transition metal impurities, in contrast to p-type boron-doped $\mathrm{Cz} \mathrm{Si}$ wafers; and ii) convenient use of a phosphorous-doped BSF and dielectric surface passivation, supporting high effective bulk diffusion length and high rear internal reflection. In addition, the phosphorous BSF allows open rear side metallisation by firing-through of a metallisation grid pattern, which results in bifacial cells that can be used for bifacial modules, and which allows the use of thin wafers.

In this article we will present recent results of process development for n-type bifacial cells, and back-contact cells based on essentially the same technology.

\section{Cell ARChitecture ANd Cell Process}

The basic cell architecture is given in Fig. 1. Information on the solar cell process has been given in [2]. The process was developed in ECN's pilot line. In June 2009, ECN, Amtech Systems, and Yingli Green Energy announced a three party research agreement, to further industrialize and develop the ntype open rear side cell. The project was dubbed "Panda". The best independently confirmed (ISE CalLab) efficiency from the Yingli pilot line is $19.5 \%$ (on $239 \mathrm{~cm}^{2}$ ). After a production expansion announced in March 2010, and a second expansion announced in October 2010, Yingli Solar now has $600 \mathrm{MW}$ of
Panda production lines operational, with $19 \%$ stable average efficiency. The production cost is nearly the same as that of standard p-type monocrystalline Si cells.

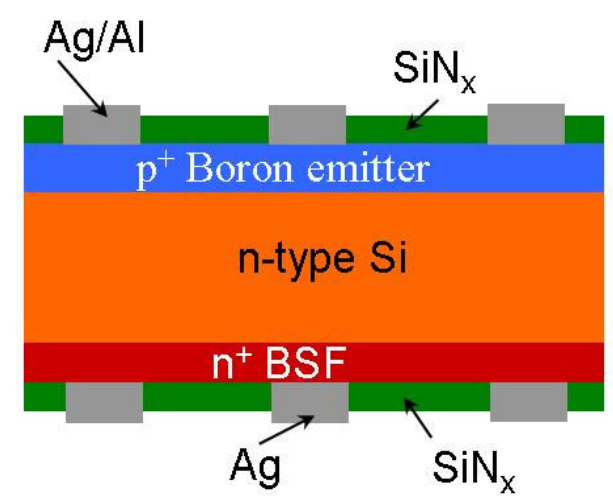

Fig. 1. Structure of the n-type cell.

\section{CONTACT RECOMBINATION}

To improve efficiency of the n-type cell, one of the possible approaches is to reduce contact recombination, on front and/or rear. Fig. 2 shows the effect of metal contacts on the Voc of the cell. The so-called 'implied Voc' is derived from light induced carrier density measurement, either on a cell halffabricate without contacts, or on a cell with contacts [3]. The implied Voc corresponds well with the actual Voc if the sample is a completed cell. It can be seen that both front and rear contact grids result in a significant reduction of Voc.

From a variety of experiments of Voc as a function of metallisation coverage, we derived, for example, that the Jo of the front contacts is about $3000 \mathrm{fA} / \mathrm{cm}^{2}$, and the impact of metal contact area on Voc is about 1.3-2.0 mV decrease per percent of increase of front metal contact area.

Table 1 shows the effect of a reduction of contact area by moving to fine-line stencil print (print results are shown in Fig. 3). The fine line print has the additional advantage of a gain of Isc. As a result, and despite a slight FF loss, the increase of cell efficiency is about $2 \%$ relative. 


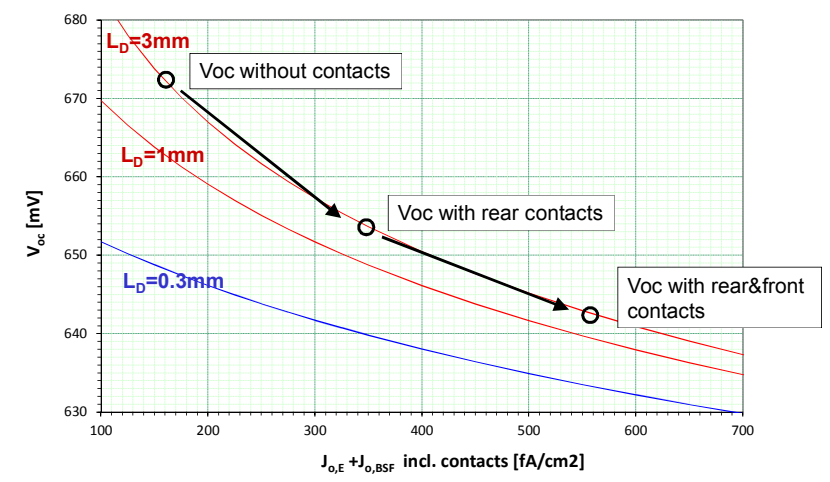

Fig. 2. Schematic of Voc and implied Voc changes due to contact recombination. The theoretical dependence of $\mathrm{Voc}$ on Jo and diffusion length $\mathrm{L}_{\mathrm{D}}$ are also shown [4].
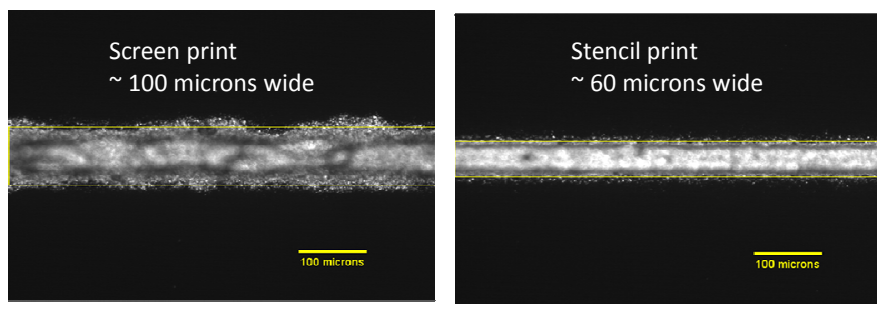

Fig. 3. Test of changing screen print by fine line stencil print.

TABLE I

EXPERIMENTALLY OBSERVED IMPROVEMENTS FROM SCREEN TO STENCIL PRINT

\begin{tabular}{|c|c|c|c|c|}
\hline & Isc (\%) & Voc (\%) & FF (\%) & $\boldsymbol{\eta}(\mathbf{\%})$ \\
\hline Test 1 & +1.5 & +0.6 & -0.4 & +1.9 \\
\hline Test 2 & +2.6 & +0.5 & -0.9 & +2.2 \\
\hline Test 3 & +2.2 & +0.4 & -0.3 & +2.3 \\
\hline
\end{tabular}

\section{REAR RECOMBINATION}

The full area BSF results in a bifacial cell with good FF. However, negative consequences of the full area BSF are increased Auger recombination, surface recombination velocity, and free carrier absorption. Therefore we have developed and tested improved BSF to reduce these effects. Fig. 4 shows the effect of reduction of BSF dopant concentration on implied Voc. By increasing Rsheet of the BSF, there is a significant increase of implied Voc due to reduction of Auger recombination and reduction of surface recombination velcocity. Fig. 5 shows that also the free carrier absorption is reduced, as demonstrated by an increase of front escape reflectance [5].

The so-far best BSF results in a significant improvement of cell efficiency by about $0.4 \%$ absolute. Combining the fine line stencil print with the optimized BSF results in a cell efficiency of $20 \%$, as shown in table II [5]. All cell results shown in this paper are based on in-house measurements with class AAA tester on an highly reflective and conductive chuck, against an externally calibrated reference cell.

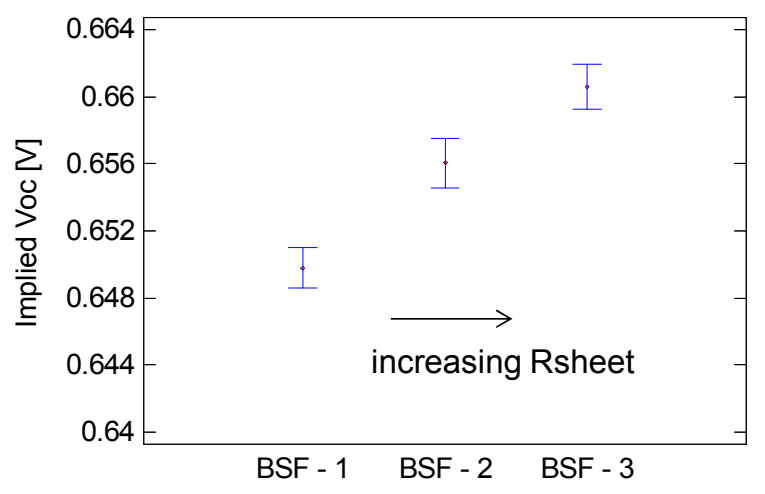

Fig. 4. Implied Voc of cell half-fabricates with 3 different BSF profiles with increasing Rsheet.

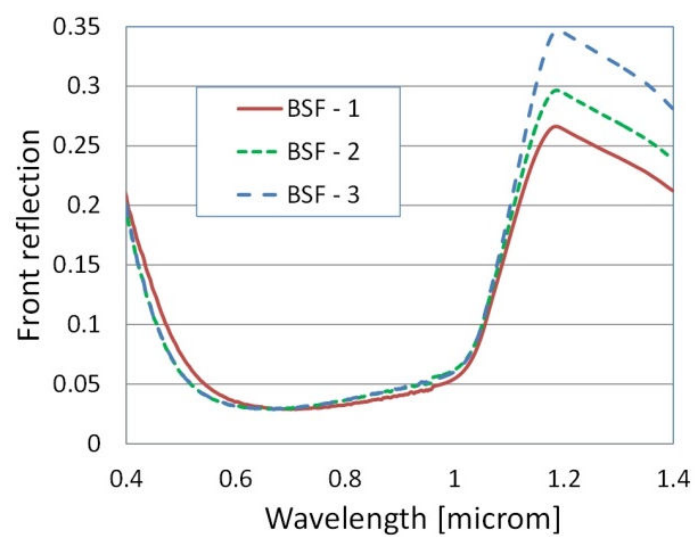

Fig. 5. Front reflection spectra of cells with 3 different BSF profiles with increasing Rsheet.

TABLE II

EXPERIMENTAL RESULTS OF THE COMBINATION OF IMPROVED BSF AND STENCIL PRINTED METALLIZATION

\begin{tabular}{|r|c|c|c|c|}
\hline & $\begin{array}{c}\text { Jsc } \\
\left(\mathbf{m A} / \mathbf{c m}^{\mathbf{2}}\right)\end{array}$ & Voc (V) & FF & $\boldsymbol{\eta} \mathbf{( \% )}$ \\
\hline Standard rear, avg & 38.7 & 0.640 & 0.784 & 19.4 \\
\hline max & 38.8 & 0.640 & 0.787 & 19.5 \\
\hline Improved rear, avg & 39.2 & 0.648 & 0.780 & 19.8 \\
\hline $\max$ & 39.3 & 0.649 & 0.783 & 20.0 \\
\hline
\end{tabular}

\section{Back CONTACT TEChNOLOGY}

Metal-wrap-through (MWT) cell technology represents a comparatively small modification of mainstream Si PV process technology, but results in significant progress to highefficiency rear-contact cell and module technology. The technology builds on standard 'H-pattern front contact' cell technology by adding a small number (10-30) of via-holes to wrap the front metallisation to the rear contacts for module interconnection. It increases the module efficiency by reduced shading loss $(\sim 2-3 \%)$, reduced series resistance $(\sim 3 \%)$, and reduced module inactive area. Fig. 6 shows a schematic layout of the MWT cell and module technology from ECN. 
The advantages of the MWT technology are large: apart from the increase in cell and module efficiency, the module manufacturing can be done with higher yield, higher degree of automation and much smaller equipment footprint. Also, the MWT technology reduces stress from the interconnection process and thus allows thinner cells, offering additional cost reduction possibilities. Advances in mainstream H-pattern cell equipment and technology, such as selective emitter technology, can easily be incorporated in MWT.

ECN published preliminary results of combining metalwrap-through with the $n$-type bifacial $n$-type cell process to result in n-type metal-wrap-through ("n-MWT") technology, in e.g. [6]. ECN, Yingli Green Energy, and Amtech Systems collaborate on further development and industrialisation of the n-MWT technology [7]

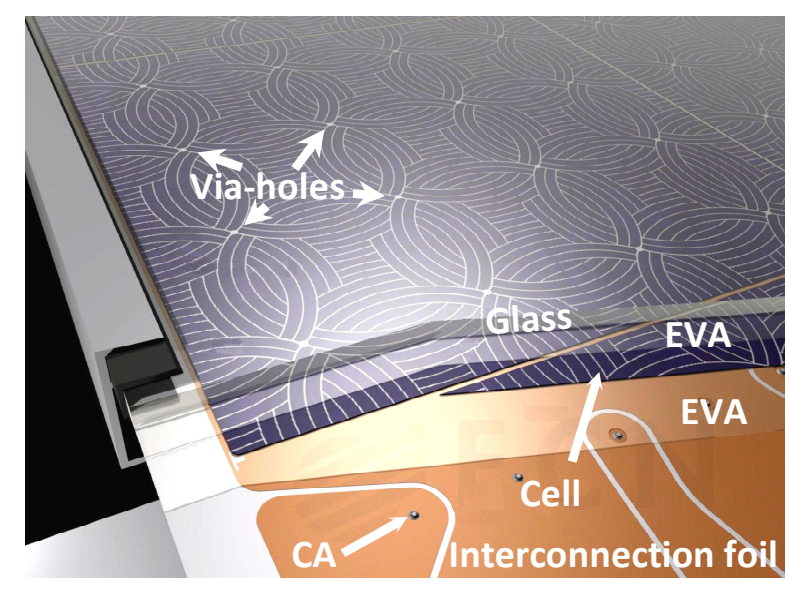

Fig. 6. Schematic 3D cross section of an MWT module manufactured using the ECN module interconnection technology.

The improvements of front metallisation and BSF, that were described above, have not yet been incorporated in the nMWT technology. Best results without these improvements are given in Table III. The FF of the MWT cells is a matter of attention, and modeling shows that it can be improved considerably. The significant increase of Voc for n-MWT cells is due to the reduction of contact recombination, as described in section II. The efficiency gain of about $0.2-0.3 \%$ is in agreement with model calculations, and can be improved by further optimization (see also [7]).

An experimental 60-cell n-MWT module according to the technology described here, demonstrated a cell-to-module FFloss of only $0.8 \%$ absolute, compared to $3 \%$ for a corresponding module of tabbed non-back-contact cells [8]. The power gain for the n-MWT module was $8 \mathrm{Wp}$ compared to the tabbed non-back-contact module. This power gain can be increased by improving the reflectivity of the MWT interconnection foil. A first improvement of the foil reflectivitiy resulted already in approx. $1 \%$ improvement of cell-to-module Isc.
TABLE III

DIRECT EXPERIMENTAL COMPARISON OF N-TYPE BIFACIAL STANDARD (NON-BACK-CONTACT) AND MWT CELLS

\begin{tabular}{|r|c|c|c|c|}
\hline & $\begin{array}{c}\text { Jsc } \\
\text { (mA/cm }\end{array}$ & Voc $\mathbf{~} \mathbf{~ V ) ~}$ & FF & $\boldsymbol{\eta}(\mathbf{\%})$ \\
\hline $\begin{array}{r}\text { "Standard" n-type, } \\
\text { avg }\end{array}$ & 38.4 & 0.638 & $0.791^{*}$ & 19.4 \\
\hline max & 38.5 & 0.638 & $0.792^{*}$ & 19.5 \\
\hline n-type MWT, avg & 39.5 & 0.644 & 0.771 & 19.6 \\
\hline max & 39.6 & 0.644 & 0.772 & 19.7 \\
\hline
\end{tabular}

${ }^{*}$ indicates $\mathrm{FF}$ is overestimated by approx. $0.2 \%$ abs due to shorting of the rear grid on the electrically conducting measurement chuck.

\section{CONCLUSION}

We have presented results of two improvements in key aspects that limit n-type Si bifacial cell efficiency: front contact recombination, and rear recombination and free carrier absorption related to the BSF. The improvements each resulted in a cell efficiency increase of about $0.4 \%$ absolute. As a result a best $n$-type Si cell efficiency of $20 \%$ was achieved.

We have also demonstrated an n-MWT cell process resulting in $0.2-0.3 \%$ absolute higher efficiency than the corresponding non-back-contact cell process (as yet still without the front metallisation and BSF improvements), and reached cell-to-module FF-loss of less than $1 \%$ absolute for a 60-cell n-MWT module.

We think the bifacial and MWT n-type Si cell processes strike a good balance between high efficiency and low-cost manufacturability, and have become (in the case of MWT: have the potential to become) a viable competitor within the range of technologies available and those being on the verge of entering the market. In addition, as we have shown by examples in this paper, there is clearly room for further development and improvement of the technology.

\section{ACKNOWLEDGMENT}

Part of this work was supported by AgentschapNL in the "International Innovation" programme (contract OM092001).

\section{REFERENCES}

[1] see also D. Song, J. Xiong, Z. Hu, G. Li, H. Wang, H. An, B. $\mathrm{Yu}, \mathrm{B}$. Grenko, K. Borden, K. Sauer, T. Roessler, J. Cui, H. Wang, J. Bultman, A.H.G. Vlooswijk, and P.R. Venema, "Progress in N-type Si Solar Cell and Module Technology for High Efficiency and Low Cost", in 38th IEEE Photovoltaic Specialist Conference, 2012, submitted.

[2] A.R. Burgers, L.J. Geerligs, A.J. Carr, A. Gutjahr, D.S. Saynova, J. Xiong, G. Li, Z. Xu, H. Wang, H. An, Z. Hu, P.R. Venema, and A.H.G. Vlooswijk, " $19.5 \%$ efficient n-type $\mathrm{Si}$ solar cells made in production", in 26th European Photovoltaic Solar Energy Conference, 2011, pp. 1144-1147. 
[3] R.A. Sinton, A. Cuevas, and M. Stuckings, "Quasisteady-state photoconductance, a new method for solar cell characterisation" in 25th IEEE Photovoltaic Specialist Conference, 1996, pp. 457460.

[4] L.J. Geerligs, N. Guillevin, and I.G. Romijn, "Progression of ntype base crystalline silicon solar cells", Photovoltaics International, 12, pp. 94-100, 2011.

[5] I. Romijn, L. Fang, A. Vlooswijk, "Industrial n-type solar cells: Towards 20\% efficiency", Photovoltaics International, 15, pp. 63-69, 2012.

[6] N. Guillevin, L.J. Geerligs, R.C.G Naber, W. Eerenstein, A.W. Weeber, "High efficiency n-type metal wrap through Si solar cells for low-cost industrial production", in 25th European Photovoltaic Solar Energy Conference, 2010, pp. 1429-1431.

[7] see also W. Zhao, J. Wang, Y. Shen, Z. Wang, Y. Chen, Z. Hu, G. Li, J. Chen, J. Xiong, N. Guillevin, B.J.B. Heurtault, L.J. Geerligs, A.W. Weeber, and J.H. Bultman, " $0.35 \%$ Absolute efficiency gain of bifacial N-type Si Solar cells by industrial metal wrap through technology", in 38th IEEE Photovoltaic Specialist Conference, 2012, submitted.

[8] N. Guillevin, B.J.B. Heurtault, B.B Van Aken, I.J. Bennett, M.J. Jansen, L. Berkeveld, L.J. Geerligs, A.W. Weeber, J.H. Bultman, Z. Hu, G. Li, W. Zhao, J. Wang, Z. Wang, Y. Chen, Y. Shen, J. Chen, B. Yu, S. Tian, J. Xiong, in 2nd SiPV conference, "High efficiency n-type metal wrap through cells and modules", Energy Procedia, 2012, to be published. 